
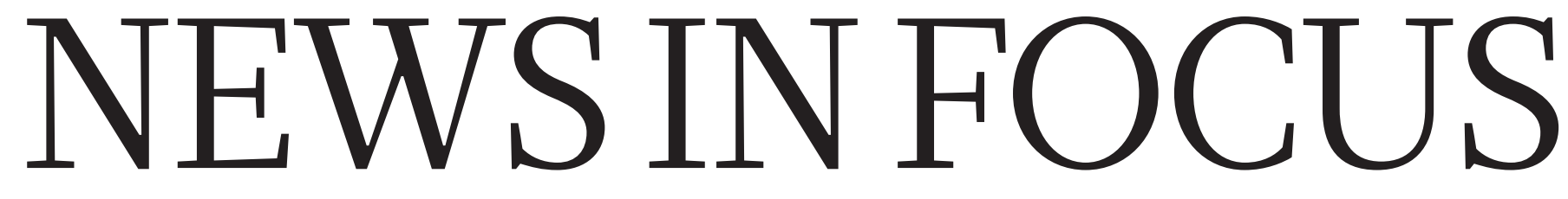

FOOD SAFETY US adds Six E. coli subtypes to the rogues' gallery $\mathbf{p . 5 5 8}$
SOCIETY With bullets and bombs, anarchists target science $\mathbf{p . 5 6 1}$
PUblic heALth The polio endgame is on - but $\$ 1$ billion short $\mathbf{p . 5 6 3}$

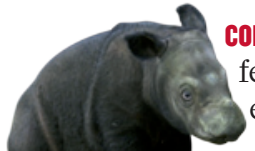

CONSERVATION First-class fertility treatment for endangered rhino $\mathbf{p . 5 6 6}$

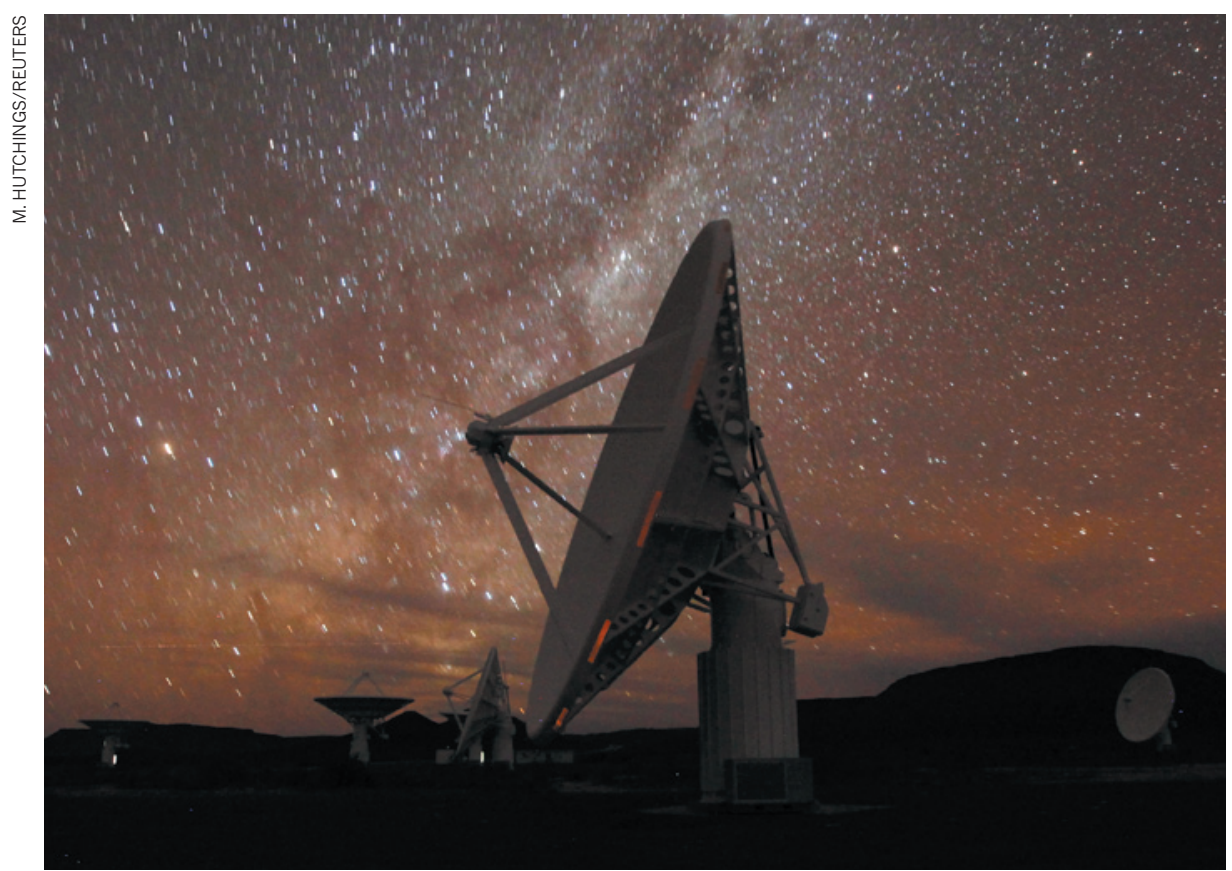

South Africa plans to build 3,000 radio dishes, with about half of them in eight other African nations.

ASTRONOMY

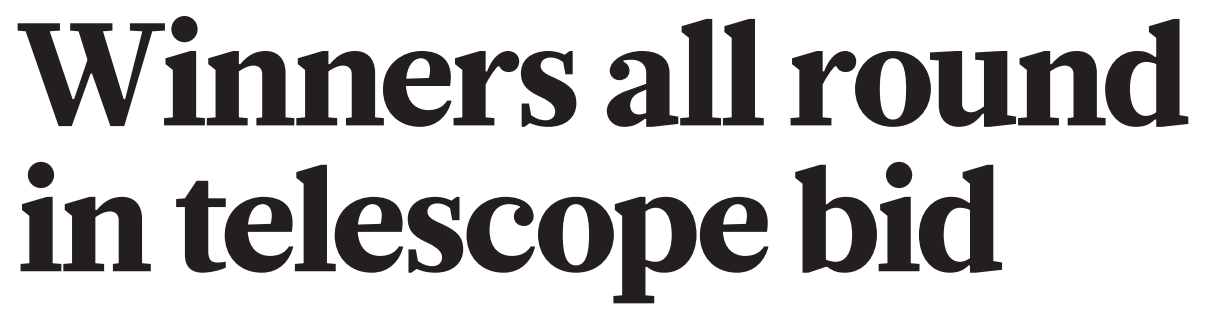

Based in both Australia and South Africa, the Square
Kilometre Array will face technical and financial challenges.

\section{BY GEOFF BRUMFIEL}

A fter months of intense political negotiation, the world's largest radio telescope has found not one home, but two. The decision has satisfied local politicians vying for the project, but has left some scientists worrying that logistical problems and cost increases could jeopardize the telescope's longterm future.

In a plan announced on 25 May, South Africa and Australia will share the Square Kilometre Array (SKA), a €1.5-billion (US\$1.9-billion) project made up of 3,000 15-metre-wide dishes and an even larger number of simple antennas. Under the deal, South Africa will host the dishes, and Australia will get the antennas. The split followed a straw poll of the voting members of the SKA board: Italy, Canada, the United Kingdom, China and the Netherlands. The nations have so far contributed a total of $€ 90$ million to the project's pre-construction phase; following the site decision, further commitments are expected to follow by 2014 .

The SKA will be dozens of times more powerful than any previous radio telescope. When completed around 2024, it will be able

to image the Universe at the time when the first stars and galaxies began to form, just a few hundred million years after the Big Bang. Its sensitivity makes it capable of spotting a television signal from a planet orbiting a nearby star (if, that is, any aliens are broadcasting).

South Africa has fought hard for the project against a joint bid by Australia and New Zealand. In March, the nation narrowly won out in a scientific assessment of the two sites (see Nature http://doi.org/hst; 2012). But many observers had expected the project to be split. Three different types of antenna technology are used to cover a wide range of frequencies between 70 megahertz and 10 gigahertz, and although the original designers envisaged that all three types would be near one another, there was no technical reason to put them together (see Nature 484, 154; 2012).

Officials from both bids welcomed the plan. "I think it's an excellent decision," says Philip Diamond, head of astronomy and space science at Australia's Commonwealth Scientific and Industrial Research Organisation in Marsfield. "We're really extremely delighted about this," adds Phil Mjwara, director general of South Africa's Department of Science and Technology.

But the division will almost certainly mean significant cost increases in the telescope's second phase of construction, scheduled for around 2018, says Heino Falcke, a radio astronomer at Radboud University in Nijmegen, the Netherlands. "The main question is: can the excess cost be offset by the fact that we have two major contributors?"

The project's sheer scale necessitates two phases of building work. In the first phase, due to begin as early as 2016, South Africa will add 190 steerable dishes to its existing MeerKAT array, according to Diamond. Australia will add 60 dishes to its SKA Pathfinder facility, and will also build half a million omnidirectional dipole antennas - cheap, stubby devices that capture radio signals across the sky and assemble them into an image. The result will be an Australian telescope with a wide-angle view of the sky, and a South African telescope with a narrower view and higher

\section{$\rightarrow$ NATURE.COM} What will SKA success mean for South Africa? go.nature.com/mcgshp sensitivity. The two will be complementary, Diamond says: the Australian telescope might pick up signals that can later be studied in detail by 
- the South African array, for example.

"This may be politically expedient, but it is also scientifically driven," says SKA board chairman John Womersley. By building on existing pilot projects in both countries, he says, the SKA's first phase will be even more powerful than originally planned. Operating across two sites will add no more than $10 \%$ to the projected $€ 350$-million cost of phase one, according to Womersley. South Africa and Australia have already each invested around US\$150 million in their respective pilot projects, and the board concluded that this added capability makes the additional investment worthwhile. First observations from these phase-one facilities could come by the end of the decade.

\section{TOUGH SELL}

In phase two, the rest of the dishes will be assembled in South Africa and eight other African countries, along with midfrequency aperture arrays that fill an observing gap between the antennas and the dishes. Meanwhile, Australia will build the remaining dipole antennas. As the SKA grows, it will require an ever-increasing amount of electricity, dedicated fibre-optic networking and supercomputing resources to channel and crunch its data. "Because we don't have a detailed design yet for phase two, it was next to impossible to estimate the costs," says Diamond. But Brian Schmidt, a Nobel-prizewinning astronomer at the Australian National University in Canberra, says that the figures he has seen suggest that the cost increase from running the project at both sites "is likely to be $30 \%$ ".

"In the current environment that's a tough sell," Schmidt warns. He hopes that if budget shortfalls or other problems make the split site impossible, the SKA's planners would reconsider the arrangement.

Albert Zijlstra, director of the Jodrell Bank Centre for Astrophysics near Manchester, UK, notes that as well as requiring coordination across six time zones, the project will essentially be creating two separate telescopes at two separate locations. With limited international funding, "they may end up competing with each other", he says.

Despite their concerns, Zijlstra, Schmidt and others generally support the decision to split the site. "When I heard the announcement, I actually suddenly decided that it's a good thing," says Andrew Lawrence, an astronomer at the University of Edinburgh, UK. Lawrence and others think that the compromise is crucial to making the project's first phase possible, by settling the long-running site dispute in a way that allows both bids to claim victory. "At this stage, I wouldn't be totally certain that phase two would ever be built," he cautions. "It's a fantastic idea, but it's still a long way from reality." — SEE EDITORIAL P.548

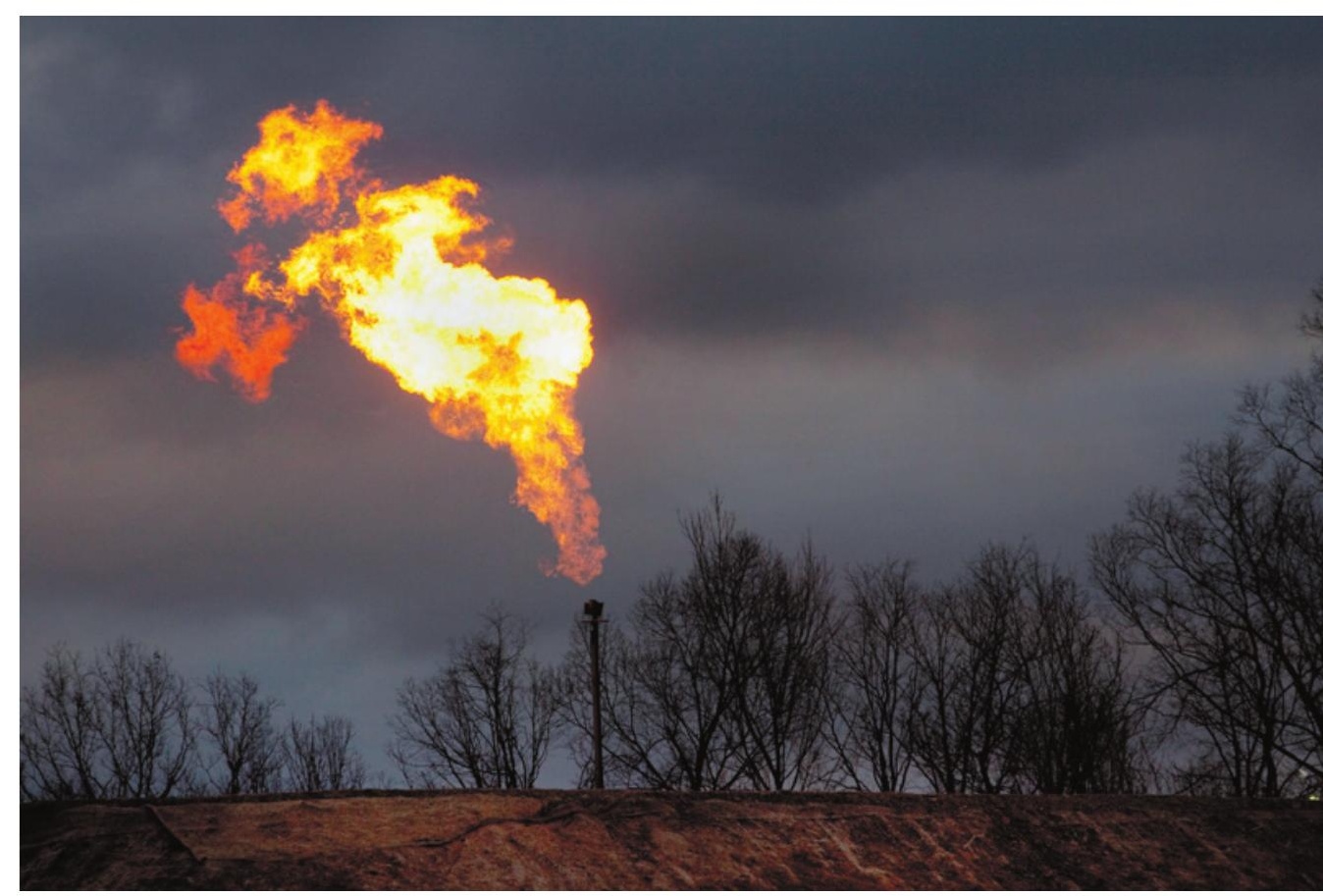

A gas flare burns at a fracking site in Bradford County, Pennsylvania.

ENVIRONMENT

\title{
Fracking boom spurs environmental audit
}

\author{
As hydraulic fracturing unlocks new gas reserves, \\ researchers struggle to understand its health implications.
}

\section{BY HELEN THOMPSON}

$\mathrm{F}$

lor Ohio, a Midwestern state hit hard by recession, the promise of an energy boom driven by hydraulic fracturing, or 'fracking', would seem to be a sure route to financial health. Far less certain is whether the technique has an impact on human health. Fracking uses high-pressure fluids to fracture shale formations deep below ground, releasing the natural gas trapped within. With the number of gas wells in Ohio that use fracking set to mushroom from 77 to more than 2,300 in the next three years, the state is the latest to try to regulate a rapidly growing industry while grappling with a serious knowledge gap. No one knows what substances - and at what levels - people near the gas fields are exposed to in the air and water, and what, if any, health threat they might pose.

In a nod to those concerns, Ohio's legislature passed a bill on 24 May, awaiting signing by the state governor as Nature went to press, that requires companies to disclose the chemicals they use during the fracking process and during

the construction and servicing of the wells. However, the bill does not compel companies to divulge a complete list of the ingredients in their fracking fluid before it is pumped underground. Some of those ingredients are deemed trade secrets, a position that troubles environmental groups and increases the problem for researchers trying to understand the risks.

"There is a real lack of data," says John Balbus, senior adviser on public health at the National Institute of Environmental Health Sciences in Bethesda, Maryland, who spoke at a workshop organized by the Institute of Medicine in Washington DC last month to discuss research strategies for studying the health impacts of gas extraction. "There's a lot of variability from region to region, in the kinds of mixtures that need to be used for the specific geology."

Fracking fluids are primarily water and

\section{$\rightarrow$ NATURE.COM}

For more on

the fracking

debate, see:

go.nature.com/ongx2b sand, but they also contain chemical additives that aid the horizontal fracturing of shale and the release of natural gas. Some components, 